\title{
Manufacturing of highly ordered porous anodic alumina with conical pore shape and tunable interpore distance in the range of $550 \mathrm{~nm}$ to $650 \mathrm{~nm}$
}

\author{
MAŁgORZATA NoREK*, MAKSYM ŁAŻEWSKI \\ Department of Advanced Materials and Technologies, Faculty of Advanced Technologies and Chemistry, \\ Military University of Technology, 2 Kaliskiego St., 00-908 Warszawa, Poland
}

\begin{abstract}
In this work, highly ordered porous anodic alumina (PAA) with tapered pore structure and interpore distance $\left(\mathrm{D}_{\mathrm{c}}\right)$ in the range of $550 \mathrm{~nm}$ to $650 \mathrm{~nm}$ were fabricated. To produce hexagonal close-packed pore structure a two-step process, combining anodization in etidronic acid electrolyte in the first step and high-concentration, high-temperature anodization in citric acid electrolyte in the second step, was applied. The Al pre-patterned surface obtained in the first anodization was used to produce regular tapered pore arrays by subsequent and alternating anodization in $20 \mathrm{wt} . \%$ citric acid solution and pore wall etching in $10 \mathrm{wt} . \%$ phosphoric acid solution. The height of the tapered pores was ranging between $2.5 \mu \mathrm{m}$ and $8.0 \mu \mathrm{m}$ for the PAA with $D_{c}=550 \mathrm{~nm}$ and $D_{c}=650 \mathrm{~nm}$, respectively. The geometry of the obtained graded structure can be used for a production of efficient antireflective coatings operating in IR spectral region.
\end{abstract}

Keywords: porous anodic alumina; guided anodization; citric acid; etidronic acid; tapered pores; AR coatings

\section{Introduction}

For decades, extensive research has been conducted to find an optimal material and its geometry for an ideal antireflective (AR) coating to maximize light entrapment in the desired spectral region and to obtain better performance of various optical devices such as solar cells, light detectors, LEDs and many others $[1,2]$. For many aerospace and military applications including night vision devises, active and passive imaging sensors, IR camouflage, or laser communication systems, the AR coatings are particularly important due to high refractive indices of materials used in the IR transmitting windows (e.g. 3.42 and 4.02 for $\mathrm{Si}$ and Ge, respectively) and, consequently, large energy losses caused by reflection $[3,4]$. The situation gets even worse for the light incidence at higher angles than the angle normal to the window.

Various strategies were developed to minimize the reflection and to achieve the best optical impedance matching between the incident

*E-mail: malgorzata.norek@wat.edu.pl angle and substrate indices, counting porous quarter wavelength AR structures [5, 6] or multilayer stacks with alternating thin films of a low and high refractive index [7, 8]. However, the nanostructured graded-index AR coatings are the most promising ones with respect to polarization insensitivity, broad-band and omnidirectional antireflectivity properties required for a perfect antireflective performance [9-14]. In these materials the optical impedance matching and, therefore, effective suppression of the reflection occurring on the surface, can be implemented via tapered index design, where the ordered array of tapered pillars acts as a layer for the gradually changing refractive indexes.

To achieve high AR performance with the tapered surface textures, optical phenomena such as diffraction and scattering must be avoided. According to the effective medium theory (EMT), in order to avoid energy loss to diffracted orders, the period of protrusions $\mathrm{p}$ must always be smaller than the incident wavelength $\lambda$ divided by the refractive index of the substrate ns [15, 16]. Moreover, the EMT predicts that better light 
entrapment will occur for larger pillar heights as long as $\mathrm{p} \ll \lambda / \mathrm{ns}$. It was shown previously that transmission at long wavelengths is governed by the pillar height $[17,18]$. The height of the surface structures should be also sufficient to ensure a slowly varying volume fraction change.

Tapered structure materials are usually prepared by time-consuming and expensive methods, which frequently involve two techniques, such as colloidal lithography and reactive ion etching RIE [19]. Porous anodic alumina (PAA) is easy to prepare and allows for a precise manipulation of pore geometry within a broad range of dimensions [20]. The PAA with tapered pore structure and interpore distance $D_{c}$ in the range of $100 \mathrm{~nm}$ to $490 \mathrm{~nm}$ were previously fabricated [2124]. The alumina taper-nanopores were used for preparing polymer AR coatings operating in visible and NIR range via template imprinting technique $[18,25,26]$. For an AR coating working at longer wavelengths, however, a larger pore spacing is needed $[3,4,17]$. Larger pore spacing means also the possibility to design tapered pores with a larger area of the cone base. Since the heights of pillars are very important at longer wavelength region, the larger area of the cone base makes it possible to obtain better graduation of refractive index along the pore walls for relatively high pores. Self-ordered PAA with $\mathrm{D}_{\mathrm{c}}>500 \mathrm{~nm}$ and parallel pores (constant pore diameter throughout the PAA thickness) have previously been synthesized [27-30].

In this work, the fabrication of highly ordered PAA with conical pore shape (variable pore diameter throughout the PAA thickness), with $\mathrm{D}_{\mathrm{c}}$ in the range of $550 \mathrm{~nm}$ to $650 \mathrm{~nm}$ and the pore height between $2.5 \mu \mathrm{m}$ and $8 \mu \mathrm{m}$, is presented. The method is based on a two-step anodization, combining anodization in etidronic acid in the first step and hightemperature, high-concentration citric acid anodizing in the second step. The guided anodization in citric acid resulted in a production of close-packed 2D hexagonal arrays of pores, which for this electrolyte has not been reported before.

\section{Experimental}

High-purity aluminum foil (99.9995 \% Al, Goodfellow, UK) with a thickness of about $0.25 \mathrm{~mm}$ was cut into rectangular specimens $(2 \mathrm{~cm} \times 1 \mathrm{~cm})$. Before the anodization process, the $\mathrm{Al}$ foils were degreased in acetone and ethanol and subsequently electropolished in a 1:4 mixture of $60 \% \mathrm{HClO}_{4}$ and ethanol at $0{ }^{\circ} \mathrm{C}$, constant voltage of $20 \mathrm{~V}$, for $2.5 \mathrm{~min}$. Next, the samples were rinsed with a distilled water, ethanol and dried. As prepared Al specimens were insulated at the back and the edges with an acid resistant tape, and served as the anode. A Pt grid was used as a cathode and the distance between both electrodes was kept constant (ca. $5 \mathrm{~cm}$ ). A large, $1 \mathrm{~L}$ electrochemical cell and a cooling bath thermostat (model MPC-K6, Huber Company) were employed in the anodizing process. An adjustable DC power supply with voltage range of $0 \mathrm{~V}$ to $300 \mathrm{~V}$ and current range of $0 \mathrm{~A}$ to 5 A, model GEN750 TDK Lambda, purchased from NDN, was used to control the applied voltage, and APPA 207 TRUE RMS multimeters were used to measure and transfer the registered current and potential data to a computer.

The first anodization was carried out in $0.3 \mathrm{M}$ etidronic acid solution (Sigma-Aldrich) at $210 \mathrm{~V}$, $235 \mathrm{~V}$, and $260 \mathrm{~V}$ and temperature of $38^{\circ} \mathrm{C}, 27^{\circ} \mathrm{C}$ and $21{ }^{\circ} \mathrm{C}$, respectively (the samples will be denoted by the numbers 1, 2 and 3, respectively). The as-obtained alumina was chemically removed in a mixture of $6 \mathrm{wt} . \%$ phosphoric acid and $1.8 \mathrm{wt} . \%$ chromic acid at $60{ }^{\circ} \mathrm{C}$ for $180 \mathrm{~min}$. Second anodization was performed in $20 \mathrm{wt} . \%$ citric acid solution under different anodizing voltages and temperatures: the sample 1 was anodized at $210 \mathrm{~V}$ and $\mathrm{T}=35^{\circ} \mathrm{C}$, the sample 2 was anodized at $230 \mathrm{~V}$ and $\mathrm{T}=35^{\circ} \mathrm{C}$, whereas the sample 3 was anodized at $250 \mathrm{~V}$ and $\mathrm{T}=33^{\circ} \mathrm{C}$. For etching of the pore walls, a $10 \mathrm{wt} . \%$ solution of phosphoric acid was used.

Morphology of PAAs was studied using fieldemission scanning electron microscope FE-SEM (FEI, Quanta) equipped with energy dispersive $\mathrm{X}$-ray spectrometer (EDS).

To obtain geometrical parameters of the fabricated Al nano-concaves, Fast Fourier transforms 
(FFTs) were generated based on three SEM images taken at the same magnification for every anodizing voltage, and were further used in calculations with WSxM Software [31]. The average interpore distance $D_{c}$ was estimated as an inverse of the FFT's radial average from three FE-SEM images for each sample [32-34].

\section{Results and discussion}

The current density $i_{a}$ vs. time curves for the aluminum specimens anodized in $0.3 \mathrm{M}$ etidronic acid solution at voltages of $210 \mathrm{~V}, 235 \mathrm{~V}$ and $260 \mathrm{~V}$ are presented in Fig. 1.

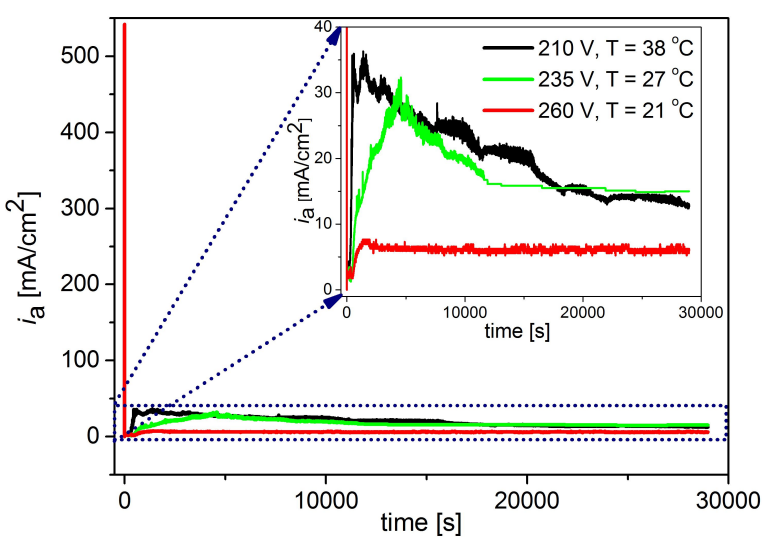

Fig. 1. Current density $i_{a}$ vs. time curves registered during the first anodization in $0.3 \mathrm{M}$ etidronic acid electrolyte.

Anodization of aluminum in etidronic acid electrolyte at various conditions was studied in detail in the literature [27]. The anodization starts at lower voltage ( $80 \mathrm{~V}$ in our case) and the voltage is immediately increased to a target value within $2 \mathrm{~min}$ to $3 \mathrm{~min}$. Then, the samples are anodized at a constant voltage for $8 \mathrm{~h}$. Typically, the longer the anodization time the better the hexagonal pore arrangement. Despite some difference in the $i_{a}-$ time curves, common trends in the current course can also be observed. In general, the current density initially increases up to a maximum value, then there is a period of current decrease, and finally, the current density reaches a steady value. In the samples 1 and 2, the period of $i_{a}$ decrease is much longer than in the sample 3 . This is probably due to the anodization conditions which are closer to the localized dielectric breakdown in the samples 1 and 2 [35]. In Fig. 2, the morphology of the resulted PAA is shown.
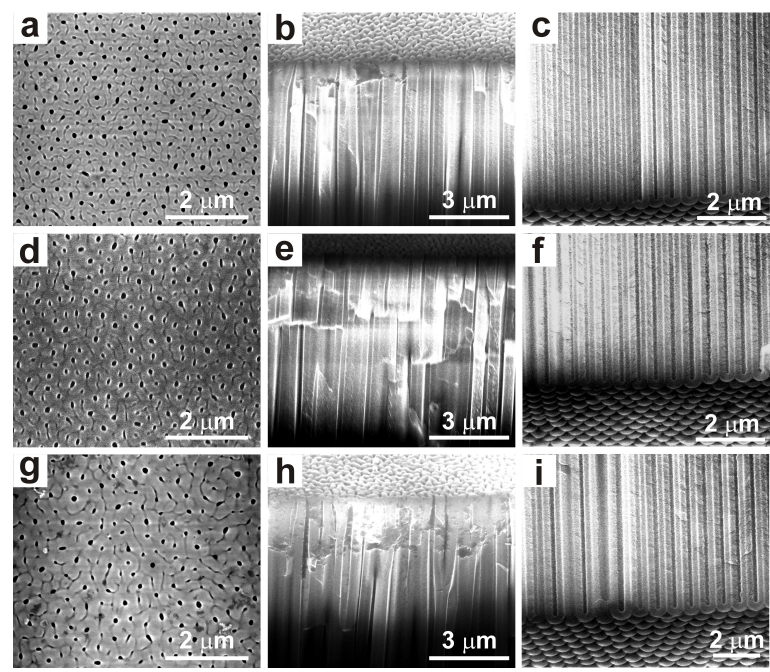

Fig. 2. SEM images of the PAA obtained after the etidronic acid anodization: the top view of the PAA membrane for the samples anodized at $210 \mathrm{~V}$ (a), $235 \mathrm{~V}$ (d), and $260 \mathrm{~V}$ (g); a cross sectional view of the top part of the PAA anodized at $210 \mathrm{~V} \mathrm{(b),} 235 \mathrm{~V}$ e), and $260 \mathrm{~V}(\mathrm{~h})$; a cross sectional view of the bottom part of the PAA anodized at $210 \mathrm{~V}$ (c), $235 \mathrm{~V}$ (f), and $260 \mathrm{~V}$ (i).

As characteristic of the first anodization step and owing to the voltage change at the beginning of the process, the top part of the resulted PAA is strongly disordered (Fig. 2a, Fig. 2d, Fig. 2g). The pore disorder is maintained down to a certain thickness of the PAA membranes (Fig. 2b, Fig. 2e, Fig. 2h). However, the SEM images of the bottom part of the produced PAA clearly demonstrate that after a prolonged anodization time the pores become perfectly aligned forming straight nanochannels perpendicular to the substrate (Fig. 2c, Fig. 2f, Fig. 2i).

The PAA obtained in the first anodization step was removed in the mixture of phosphoric and chromic acid to obtain regular hexagonal arrays of nano-concaves on aluminum surface (Fig. 3).

The distance between the nano-concave centers $D_{c}$ was determined to be $550 \pm 11 \mathrm{~nm}, 590 \pm 9 \mathrm{~nm}$, 


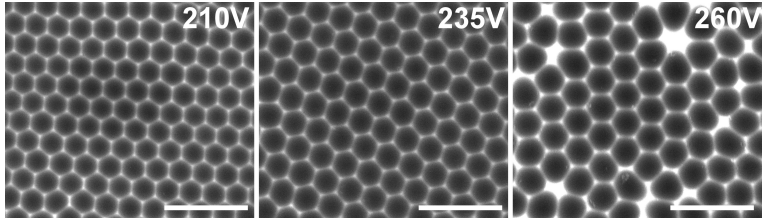

Fig. 3. SEM images of the Al nano-concave array obtained after removal of PAA fabricated by the etidronic acid anodizing at 210, 235, and $260 \mathrm{~V}$; the scale bar $=2 \mu \mathrm{m}$.

and $650 \pm 18 \mathrm{~nm}$ for samples 1,2 and 3, respectively. The Al nano-concave arrays were further used to prepare highly ordered PAA membranes with parallel pores from the top to the bottom, needed to design the graded structure. The second anodization was performed in the concentrated citric acid solution of $20 \mathrm{wt} . \%$ in order to establish a reasonable oxide growth rate. Different voltage and temperature values were applied in the second anodization in order to adjust the operating conditions to the distance between nano-concave centers on the Al surface (the applied voltage should be close to the $\mathrm{D}_{\mathrm{c}} / \zeta$, where the factor $\zeta \sim 2.5$ for mild anodization) [36, 37]. The samples 1 and 2 were anodized at $\mathrm{T}=35^{\circ} \mathrm{C}$ under the voltages of $210 \mathrm{~V}$ and $230 \mathrm{~V}$, respectively. For the $\mathrm{Al}$ nano-concaves with the largest $\mathrm{D}_{\mathrm{c}}$ (sample 3 ) the voltage of $250 \mathrm{~V}$ and $\mathrm{T}=33{ }^{\circ} \mathrm{C}$ were chosen. In Fig. $4, \mathrm{i}_{\mathrm{a}}$ vs. time transients for the samples anodized in citric acid are presented, along with the top view of the resulted PAA (insets in Fig. 4).

The current shape is characteristic of the mild anodization. In accordance with the previous studies [38, 39], three stages can be distinguished in the $\mathrm{i}_{\mathrm{a}}$-time curves: very high current density at the beginning of the process (1), its subsequent drop within few seconds (2), and finally its slower exponential decrease to a steady-state values (3). The regimes can be attributed to the following phenomena: an electrolytic reaction of water at the beginning, very rapid barrier layer formation and, at the end, a stable pores growth $[38,39]$. In the samples 2 and 3, an additional stage 4 can be observed. The current increase in the samples 2 and 3 may be due to field-enhanced or/and temperature-enhanced partial dissolution of the formed oxide (thinning of the barrier layer), which results in a rise of $i_{a}$. The $i_{a}$ at the stage 4 stabilizes, however, after the initial increase, suggesting that a dynamic equilibrium of formation and dissolving of alumina is attained and a stable growth of pores proceeds. In the studied samples, the periodic arrangement of concavities on aluminum surface serves as nucleation sites for undisturbed growth of anodic alumina and, consequently, there is no competition between pores [40, 41]. The growth position of the pores is limited by the pre-patterned design and is restricted to the inner corner/electrolyte interface, where a maximum dissolution rate of $\mathrm{Al}^{3+}$ is localized [42]. The anodization conditions applied in this study resulted in the PAAs of more regular pore arrangement than previously obtained [43-45], most probably owing to a guided role of $\mathrm{Al}$ concaves prepared in the first anodization step, which induced a transfer of the geometrical features of Al nanoconcaves, such as hexagonal pore regularity and the pitch size, to the corresponding PAAs.

In order to properly design the fabrication of tapered pore arrays for given geometrical parameters by sequential anodizing and etching steps, the pore broadening rate has to be estimated. The pore broadening was done by immersing a sample into $10 \mathrm{wt} . \% \mathrm{H}_{3} \mathrm{PO}_{4}$ solution for a given period of time at room temperature. In Fig. 5 the dependence of pore diameter on etching time is presented.

Samples 1, anodized at $210 \mathrm{~V}$ in citric acid solution, have been taken as an example. For the samples 2 and 3, however, analogous procedure was applied. The broadening process seems to be a linear function of etching time despite variable chemical composition of different parts of the unit cell $[46,47]$. The pore broadening was carried out till the maximal possible pore opening was achieved. The pore diameter increased from around $120 \mathrm{~nm}$ in as obtained sample to $\sim 530 \mathrm{~nm}$ in the sample etched for $10 \mathrm{~h}$. Thus, the pore broadening rate for each sample was estimated to be in the range of $41 \mathrm{~nm} / \mathrm{h}$ to $45 \mathrm{~nm} / \mathrm{h}$. As can be seen in the SEM images of the PAA's cross-sections, the pore broadening is uniform throughout the entire anodic oxide film thickness (insets in Fig. 5). 

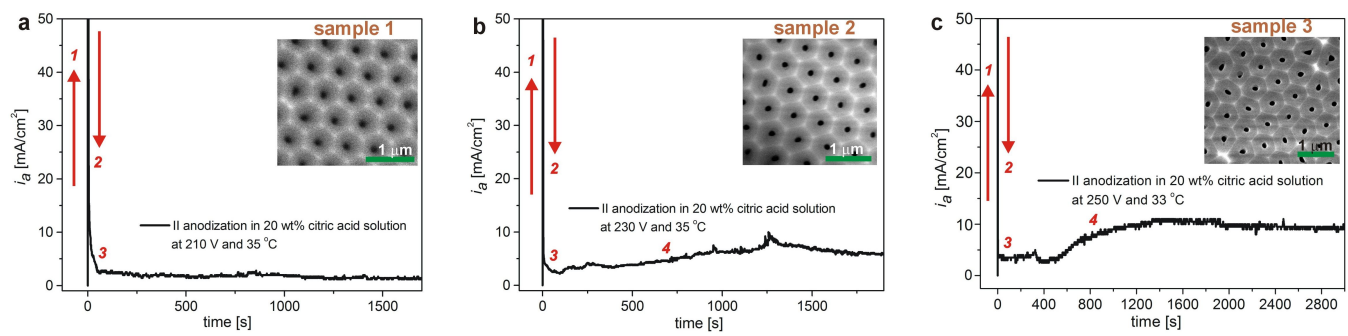

Fig. 4. Current density ( $\left.\mathrm{i}_{\mathrm{a}}\right)$ vs. time curve registered during the second anodization in $20 \mathrm{wt} . \%$ citric acid electrolyte, at $\mathrm{T}=35{ }^{\circ} \mathrm{C}$ and $210 \mathrm{~V}$ (a), $\mathrm{T}=35^{\circ} \mathrm{C}$ and $230 \mathrm{~V}$ (b), $\mathrm{T}=33{ }^{\circ} \mathrm{C}$ and $250 \mathrm{~V}$ (c); the insets demonstrate SEM images of the top view of the respective PAA membranes.

Table 1. The parameters applied in the procedure to prepare the porous anodic alumina with conical pore shape and with the following geometrical parameters: $\mathrm{D}_{\mathrm{c}} \approx 550 \mathrm{~nm}$, and pore height $\approx 2.5 \mu \mathrm{m}$ for the sample 1 ; $\mathrm{D}_{\mathrm{c}} \approx 590 \mathrm{~nm}$, and pore height $\approx 4 \mu \mathrm{m}$ for the sample $2 ; \mathrm{D}_{\mathrm{c}} \approx 650 \mathrm{~nm}$, and pore height $\approx 8 \mu \mathrm{m}$ for the sample 3 .

\begin{tabular}{|c|c|c|c|c|c|c|}
\hline & & & & \\
\hline & & & & & & \\
\hline & & $\frac{1^{\text {st }} \text { an }}{\text { Voltage [V] }}$ & $\begin{array}{l}\text { odization in etidror } \\
\text { Temperature }\left[{ }^{\circ} \mathrm{C}\right]\end{array}$ & $\begin{array}{c}\text { Anodization } \\
\text { time }[\mathrm{h}] \\
\end{array}$ & & \\
\hline & 1 & 210 & 38 & 8 & & \\
\hline & 2 & 235 & 27 & 8 & & \\
\hline & 3 & 260 & 21 & 8 & & \\
\hline \multirow{2}{*}{ Sample } & \multicolumn{6}{|c|}{$2^{\text {nd }}$ anodization in citric acid } \\
\hline & Voltage $[\mathrm{V}]$ & Temperature $\left[{ }^{\circ} \mathrm{C}\right]$ & $\begin{array}{l}\text { Anodization } \\
\text { time* }[\mathrm{min}] \\
\end{array}$ & $\begin{array}{l}\text { Anodization } \\
\text { steps }\end{array}$ & $\begin{array}{l}\text { Etching } \\
\text { time }[\mathrm{h}]\end{array}$ & $\begin{array}{c}\text { Etching } \\
\text { steps }\end{array}$ \\
\hline 1 & 210 & 35 & 5 & 10 & 1 & 9 \\
\hline 2 & 230 & 35 & 5 & 11 & 1 & 10 \\
\hline 3 & 250 & 33 & 5 & 12 & 1 & 11 \\
\hline
\end{tabular}

*Except the duration of the first anodization step which was always $15 \mathrm{~min}$.

The tapered pores were prepared by subsequent and alternating anodization of sample 1 to sample 3 in $20 \mathrm{wt} . \%$ citric acid and etching in $10 \mathrm{wt} . \%$ phosphoric acid solution. Based on the previous analysis, a time duration for anodization and etching steps could be properly estimated. The process is schematically presented in Fig. 6.

In the scheme, the etching steps were denoted by Roman numerals (I, II, ... i), whereas the anodization steps were marked by Arabic numerals $(1,2, \ldots$ i). Equal time intervals were chosen for both anodization and etching steps, except for the first anodization step. Due to a thick barrier layer, the step 1 must be longer in order to assure enough time for pore nucleation and growth. Moreover, the pore walls should be sufficiently high to avoid a complete PAA wall dissolution after the first etching step. In the studied samples the time of $15 \mathrm{~min}$ was always used in the first anodization step. The other anodization steps lasted 5 minutes, whereas each etching step lasted 1 hour. For a given anodization potential, the larger the $\mathrm{D}_{\mathrm{c}}$, the more steps should be involved in order to obtain uniform tapered pores from the top to the bottom of the PAA thickness. With anodizing potential the pore diameter increases, which was previously ascribed to the high current density and strong chemical dissolution enhanced by the electric field [33]. Therefore, the number of etching and anodizing steps in the sample 3 (anodized at $250 \mathrm{~V}$ ) was determined accordingly. In Table 1, the parameters 


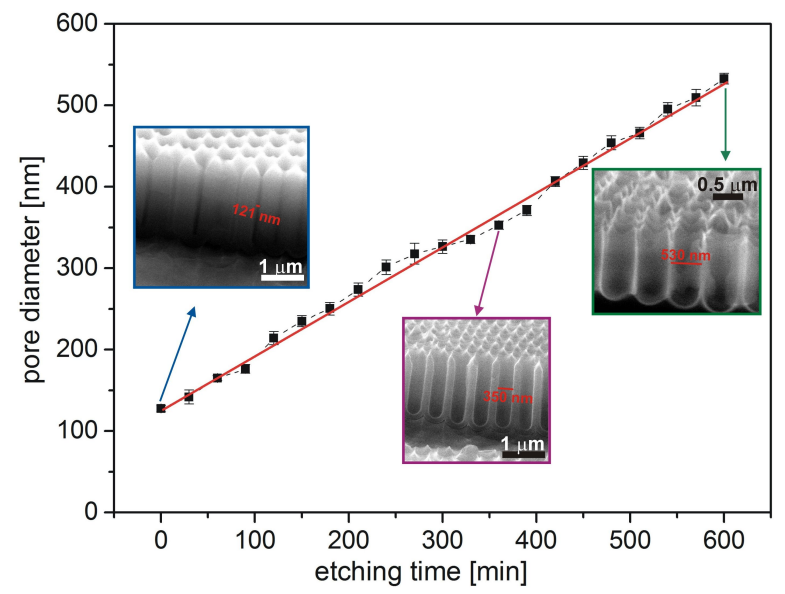

Fig. 5. Pore diameter as a function of etching time determined for sample 1; the insets show SEM images of a cross section of the PAA before, after 6-hour, and after 10-hour etching.

applied for fabrication of the PAA membranes with conical pore shape and different geometrical features are presented.

The pertinent current density vs. time curves registered during all anodization steps for the sample 1 to sample 3 are shown in Fig. 7.

The $i_{a}$ in the first anodization step is always larger as compared to the $i_{a}$ registered during the subsequent anodization steps due to formation of the barrier layer at the beginning of the process. After the first etching step, the barrier layer gets thinner and is rebuilt in the following anodization step. Since the etching time intervals are the same, the barrier layer gets thinner always by the same thickness, and consequently, the $i_{a}$ operating during the following anodization steps is kept more or less at the same level. In the $i_{a}$ time curves registered for sample 3 after the $5^{\text {th }}$ step, some disturbances in the current flow can be observed (Fig. 7c), which are probably due to an intensive electrolyte anions migration through the reduced barrier layer under the high anodizing voltage.

The resulting PAA membranes grown on the $\mathrm{Al}$ nano-concave arrays by application of the procedure presented in Fig. 6 and according to the parameters gathered in Table 1 are demonstrated in Fig. 8 .

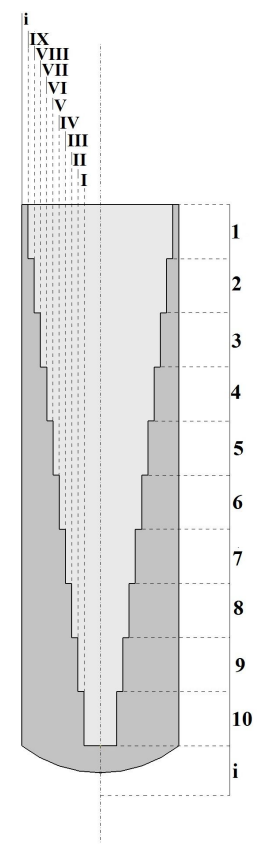

Fig. 6. Scheme representing a multi-step anodization and etching process applied for the fabrication of a tapered pore. The Arabic numerals: 1, 2, $3, \ldots$ i signify the number of anodization steps, whereas the Roman numerals: I, II, III, ... i indicate the number of etching steps.

The first row shows the top view of the PAA membranes (Fig. 8a to Fig. 8c), whereas the second row demonstrates cross-sections of the respective PAA membranes (Fig. 8d to Fig. 8f). The SEM images demonstrate an excellent hexagonal pore ordering of the conical pores. The PAA membrane thickness ranges from around $2.5 \mu \mathrm{m}$ for sample 1 up to around $8 \mu \mathrm{m}$ for sample 3 depending on the number of anodization steps and anodization conditions applied for a given sample (at higher voltages the PAA growth rate was larger). It should be mentioned that a shape and geometrical features of the pores depend strongly on the duration time of anodization and etching steps. The method allows, thus, to design various profiles of columnar pores within the limits put by the interpore distance [23]. The length of the tapered pores and the interpore distance in the PAA membrane fabricated by the method presented in this work should be sufficient to prepare antireflective coatings with good performance in the IR spectral region. The tapered porous 

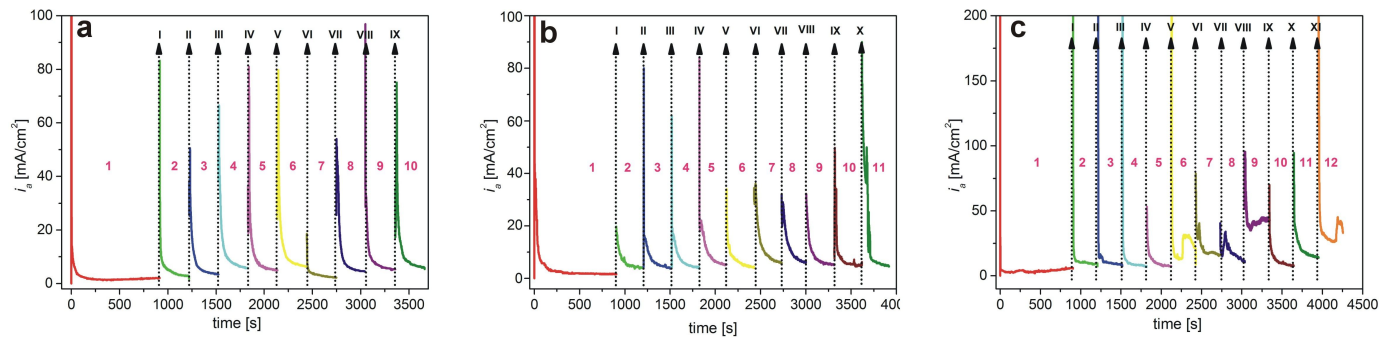

Fig. 7. Current density ( $\left.i_{a}\right)$ vs. time curves registered for the samples 1 (a), 2 (b), and 3 (c) during a multistep citric acid anodization: sample 1 anodized at $210 \mathrm{~V}\left(\mathrm{~T}=35^{\circ} \mathrm{C}\right)$, sample 2 anodized at $230 \mathrm{~V}\left(\mathrm{~T}=35^{\circ} \mathrm{C}\right)$, and sample 3 at $250 \mathrm{~V}\left(\mathrm{~T}=33^{\circ} \mathrm{C}\right)$; the etching steps are also indicated in the curves by dotted, black arrows and the respective Roman numerals.

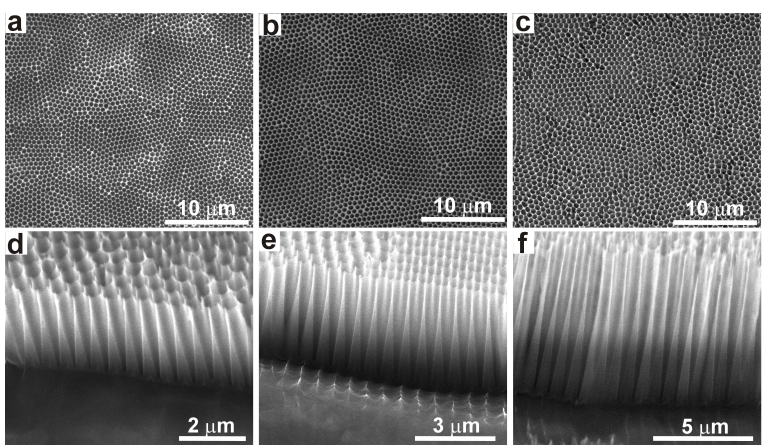

Fig. 8. SEM images of the PAA membranes with tapered pore structure: top view of the sample 1 (a), 2 (b), and 3 (c); cross sectional view of the sample 1 (d), 2 (e), and 3 (f).

templates can be then used for large scale production of durable nanostructured AR coatings on polymer substrates using nano-imprint lithography (NIL) [48].

\section{Conclusions}

In this work, highly ordered porous anodic alumina membranes with tapered pores were fabricated. The method combining anodization in etidronic acid electrolyte and high-concentration, high-temperature anodization in citric acid electrolyte was applied to produce hexagonal closepacked pore arrays with interpore distance in the range of $550 \mathrm{~nm}$ to $650 \mathrm{~nm}$. It has been demonstrated for the first time that a highly-ordered PAA membrane with regular top and bottom surfaces can be obtained by citric acid anodizing. The tapered pores were obtained by subsequent and alternating anodization of the $\mathrm{Al}$ pre-patterned surface in 20 wt.\% citric acid solution and the pore wall etching was performed in $10 \mathrm{wt} . \%$ phosphoric acid solution. The shape of the pores was tailored by time duration of the following anodization and etching steps and the number of cycles. The height of the tapered pores was around $2.5 \mu \mathrm{m}$ for the PAA with $\mathrm{D}_{\mathrm{c}}=550 \mathrm{~nm}, 4.0 \mu \mathrm{m}$ for the PAA with $\mathrm{D}_{\mathrm{c}}=590 \mathrm{~nm}$, and around $8.0 \mu \mathrm{m}$ for the PAA with $\mathrm{D}_{\mathrm{c}}=650 \mathrm{~nm}$. The geometry of the obtained graded structure should be adequate for production of efficient antireflective coating operating in IR spectral region.

\section{Acknowledgements}

The work was supported by the Polish National Science Center (Decision Number: DEC-2012/07/D/ST8/02718).

\section{References}

[1] Chattopadhyay S., Huang Y.F., Jen Y.J., GanGuly A., Chen K.H., Chen L.C., Mater. Sci. Eng. R, 69 (2010), 1.

[2] Raut H.K., Ganesh V.A., NAIR A.S., RAMAKRISHNA S., Energ. Environ. Sci., 4 (2011), 3779.

[3] Hobbs D.S., MacLeod B.D., Proc. SPIE, 5786 (2005), 349

[4] Frey B., Leviton D., Madison T., Proc. SPIE, 6273 (2006), 62732J.

[5] Guldin S., Kohn P., Stefik M., Song J., Divitini G., ECARla F., Ducati C., Wiesner U., STEINER U., Nano Lett., 13 (2013), 5329.

[6] Joo W., KIM H.J., KIM J.K., Langmuir, 26 (2010), 5110.

[7] Camargo K.C., Michels A.F., Rodembusch F.S., Horowitz F., Chem. Commun., 48 (2012), 4992.

[8] Yildrim A., KhudiYeV T., Daglar B., BUDUNOGLU H., OKYAY A.K., BAYINDIR M., ACS Appl. Mater. Inter., 5 (2013), 853. 
[9] Yanagishita T., Nishio K., Masuda H., Appl. Phys. Express, 2 (2009), 022001.

[10] Raut H.K., Dinachali S.S., Loke Y.C., GaneSAn R., Ansah-Antwi K.K., Góra A., Khoo E.H., Ganesh V.A., SAIFUllah M.S.M., RAmaKRISHNA S., ACS Nano, 9 (2015), 1305.

[11] Raut H.K., Dinachali S.S., He A.Y., Ganesh V.A., SAIFUllaH M.S.M., LAW J., RAMAKRISHNA S., Energ. Environ. Sci., 6 (2013), 1929.

[12] Rahman A., Ashraf A., Xin H., Tong X., SutTER P., Eis Aman M.D., Black C.T., Nat. Commun., 6 (2015), 5963.

[13] Asadollahbaik A., Boden S.A., Charlton M.D.B., Payne D.N.R., Cox S., Bagnall D.M., Opt. Express, 22 (2014), A402.

[14] Chen J.Y., Chang W.-L., Huang C.K., Sun K.W., Opt. Express, 19 (2011), 14411.

[15] Raguin D.H., Morris G.M., Appl. Opt., 32 (1993), 1154.

[16] Southwell W.H., J. Opt. Soc. Am. A, 8 (1991), 549.

[17] Gonzalez F.L., Gordon M.J., Opt. Express, 22 (2014), 12808.

[18] Li J., Zhu J., Gao X., Small, 10 (2014), 2578.

[19] CAI J., Qi L., Mater. Horiz., 2 (2015), 37.

[20] LEE W., LeE J.-K., Adv. Mater., 14 (2002), 1187.

[21] Li J., Li C., Gao X., Appl. Surf. Sci., 257 (2011), 10390.

[22] Li C., Li J., Chen C., Zhu J., Gao X., Chem. Commun., 48 (2012), 5100.

[23] Li J., Li C., Chen C., Hao Q., Wang Z., Zhu J., GAO X., ACS Appl. Mater. Inter., 4 (2012), 5678.

[24] Sun B., Li J., Jin X., Zhou C., Hao Q., Gao X., Electrochim. Acta, 112 (2013), 327.

[25] Choi K., Park S.H., Song Y.M., LeE Y.T., Hwangbo C.K., YAng H., LeE H.S., Adv. Mater., 22 (2010), 3713.

[26] Choi K., Park S.H., Song Y.M., Choc C., LeE H.S., J. Mater. Chem., 22 (2012), 17037.

[27] Kikuchi T., Nishinaga O., Natsui S., SuzUKi R.O., Electrochim. Acta, 156 (2015), 235.

[28] Takenaga A., Kikuchi T., Natsui S., Suzuki R.O., ECS Solid State Lett., 4 (2015), P55.

[29] Kikuchi T., Nishinaga O., Natsui S., Suzuki R.O., Appl. Surf. Sci., 34 (2015), 119.

[30] Kikuchi T., Nakajima D., Nishinaga O., NatSUI S., SuzUKi R.O., Curr. Nanosci., 11 (2015), 560.
[31] Horcas I., Fernandez R., Gomez-Rodriguez J.M., Colchero J., Gomez-Herrero J., BAro A.M., Rev. Sci. Instrum., 78 (2007), 013705.

[32] StęPNiowski W.J., NowAK-StęPNiowska A., BoJAR Z., Mater. Charact., 78 (2013), 79.

[33] StęPniowski W.J., Bojar Z., Surf. Coat. Tech., 206 (2011), 265.

[34] Stępniowski W.J., Zasada D., Bojar Z., Surf. Coat. Tech., 206 (2011), 1416.

[35] Su Z., Zhou W., Jianga F., Hong M., J. Mater. Chem., 22 (2012), 535.

[36] Keller F., Hunter M.S., Robinson D.L., J. Electrochem. Soc., 100 (1953), 411.

[37] Ebihara K., Takahashi H., Nagayama M., J. Met. Finish. Soc. Jpn., 34 (1983), 548.

[38] Parkhutik W.P., Shershulsky V.I., J. Phys. D Appl. Phys., 25 (1992), 1258.

[39] Li F.Y., Zhang L., Metzger R.M., Chem. Mater., 10 (1998), 2470.

[40] Han X.Y., Shen W.Z., J. Electroanal. Chem., 655 (2011), 56

[41] Norek M., Dopierąa M., StęPniowski W.J., J. Electroanal. Chem., 750 (2015), 79.

[42] Chen S.H., Chan D.-S., Chen C.-K., Chang T.-H., LaI Y.-H., LeE C.-C., Jpn. J. Appl. Phys., 49 (2010), 015201

[43] Wang Q., Long Y., Sun B., J. Porous Mat., 20 (2013), 785.

[44] Bellemare J., Sirois F., Ménard D., J. Electrochem. Soc., 161 (2014), E75.

[45] Chen X., Yu D., CaO L., Zhu X., Song Y., Huang H., Lu L., Chen X., Mater. Res. Bull., 57 (2014), 116.

[46] Coz le F., Arurault L., Datas L., Mater. Charact., 61 (2010), 283.

[47] Wada K., Shimohira T., Yamada M., Baba N., $J$. Mater. Sci., 21 (1986), 3810.

[48] Burghoorn M., Roosen-Melsen D., Riet de J., SABIK S., VRoon Z., YAKimets I., Buskens P., Materials, 6 (2013), 3710.

Received 2016-10-22 Accepted 2017-05-03 